\title{
Destino dos Afetos no Rorschach de Mulheres Vítimas de Incesto
}

\author{
Anne Valérie Mazoyer ${ }^{1}$ (D), Marjorie Roques ${ }^{2}$ (D), \\ Deise Matos do Amparo ${ }^{3, *}$ (D), \& Camila Taunay ${ }^{3}$ (D) \\ ${ }^{1}$ Universidade de Toulouse, Toulouse, França \\ ${ }^{2}$ Universidade de Caen, Caen, França \\ ${ }^{3}$ Universidade de Brasília, Brasília, DF, Brasil
}

\begin{abstract}
RESUMO - Este estudo tem como objetivo analisar o destino e a dinâmica dos afetos em mulheres adultas que sofreram incesto paterno na infância e adolescência. Apoiando-nos nos conceitos de afeto e trauma da psicanálise, levantamos a hipótese de que o incesto desorganiza as capacidades psíquicas das vítimas e suas vivências afetivas. Realizamos um estudo descritivo-exploratório de casos múltiplos com mulheres francesas utilizando entrevistas e o Método Projetivo de Rorschach (Escola de Paris). Essas mulheres apresentam um modo particular de expressar afetos, nem sempre sintônico com a representação devido à gravidade da clivagem. Assim, há uma distorção do afeto com perda da sua qualidade psíquica. Concluímos pela necessidade de acompanhamento terapêutico baseado nas capacidades de identificar, reconhecer e manejar os afetos.
\end{abstract}

PALAVRAS-CHAVE: Rorschach, afeto, incesto, trauma, psicoterapia

\section{The Fate of Affections in the Rorschach of Women Victims of Incest}

\begin{abstract}
This article aims to analyze the fate and dynamics of affections in adult women who suffered paternal incest during their childhood and adolescence. Based on the concept of affection and trauma in psychoanalysis, we hypothesized that incest disorganizes psychological capacities and affective experiences of the victims. We conducted an exploratorydescriptive study of multiple cases with French women using interviews and the Rorschach Projective Method (Parisian School). These women have a particular way of expressing affections, not always in sync with representation, due to the severity of the splitting. Therefore, there is a distortion of affection with the loss of its psychic quality. We conclude that therapeutic follow-up, based on the ability to identify, recognize and manage affections is deemed necessary.
\end{abstract}

KEYWORDS: Rorschach, affection, incest, traumas, psychotherapy

\section{ABORDAGEM PSICANALÍTICA DO INCESTO PATERNAL}

A violação da intimidade pelo abuso sexual incestuoso pode produzir um assassinato da identidade, aniquilar o sentimento de si, provocar a perda do caráter animado do sujeito e levar à despersonalização ou dissociação (Balier, 1994). Como descreve Roussillon (2002), o abuso sexual incestuoso, derivado do encontro traumática entre a realidade e a vida fantasmática edípica, pode fazer vacilar as fronteiras psíquicas desencadeando uma confusão entre fantasma, representação psíquica e ato. Esse traumatismo narcísico, caracterizado por um fluxo de excitações vivenciado passivamente e gerado por uma situação na qual o sujeito não pode reagir adequadamente, é capaz de levar a experiências de congelamento, excesso ou transbordamento psíquico. Segundo Janin (1985), o núcleo frio e quente do trauma.

*E-mail: deise.amparo.matos@gmail.com

- Submetido: 10/10/2019; Revisado: 21/01/2020; Aceito: 25/03/2020. 
No caso do incesto, dependendo do momento de desenvolvimento da criança em que ele foi realizado, há um prejuízo da organização edípica e o psiquismo tem dificuldade de se estruturar, produzindo o que Janin (1996) denomina de colapso tópico no aparelho psíquico. Isso provoca inevitavelmente uma dificuldade em criar um espaço transicional em relação à realidade. Nesse colapso, a clivagem entre duas posições antagônicas se instala e, para sobreviver psiquicamente, o sujeito se organiza despossuído dele mesmo e se submete ao parente abusador. Nesse processo de interiorização do agressor, a criança atribui a si mesma o desejo incestuoso que não lhe pertence. Ela carrega a culpa parental ao ponto de pensar em si mesma como protagonista, autora da sedução e provocadora da excitação no progenitor, passando assim a inocentá-lo. Não obstante, ressaltamos que essa culpabilidade sentida pela criança possui um papel defensivo, retirando-a do lugar de objeto submisso, sentido de forma traumática durante o abuso, e tornando-a protagonista da sua história, por mais traumática que seja (Roman \& Baron, 2004).

$\mathrm{O}$ incesto provoca necessariamente uma confusão das imagos parentais (Bollas, 1996) que pode criar um obstáculo para a instalação das referências edípicas e prejudicar, por sua vez, a constituição do pubertário e da identidade feminina (Agostini, 2000). O ódio sentido pelo pai abusador - mas também pela mãe, cúmplice inconsciente - é voltado para si, a fim de tentar preservar os progenitores de toda agressividade.

Do ponto de vista psicopatológico, a adolescente ou mulher que passa pelo incesto pode ser levada, pela via do afeto melancólico, a recorrer a condutas masoquistas para punir o próprio corpo vivenciado como sedutor (Chabert, 2003a). O desejo e a pulsão passam a ser considerados como perigosos por serem ativadores do traumatismo. $\mathrm{O}$ fechamento sobre si, na depressão, é então privilegiado, mesmo empobrecendo o Eu e a vida fantasmática. Na clínica do incesto, Parat (2011) insiste em falar sobre uma privação de simbolização do afeto devido à incapacidade de distinção entre o sonho e a realidade.

A clínica do incesto nos convida a refletir sobre as modalidades de trabalhos terapêuticos possíveis com as mulheres que foram vítimas de abuso sexual na infância e adolescência. Um dos eixos de aproximação dessa clínica refere-se à abordagem do estado afetivo, uma vez que o trauma pode conter um impacto inegligenciável tanto na organização psíquicossomática como no desenvolvimento psíquico das vítimas (Parat, 2004, 2011). Nas psicoterapias de jovens mulheres que foram abusadas na infância, evidencia-se a repressão afetiva com a presença de sentimentos de vergonha, impureza e culpa. No entanto, é importante salientar que o impacto da violência sexual não é unívoco e depende do tipo de abuso, da sua frequência, da fragilidade psíquica anterior e dos mecanismos de defesa organizados pelo próprio sujeito abusado.

Devemos especialmente a Ferenczi (1933/2004) a compreensão do alcance do trauma na vida psíquica. A partir de seu trabalho clínico desenvolvido com pacientes vulneráveis, esse autor ressaltou a confusão de línguas entre ternura e paixão, entre a criança e o adulto abusador, com sua consequente intrusão no psiquismo, são consequências nefastas do trauma que vêm a se configurar na vida afetivoemocional da criança. Nesses casos, por intermédio desse adulto que deveria exercer o papel de protetor, a criança vem a duvidar da realidade daquilo que vivenciou e sentiu (ela dissocia). Ferenczi ressalta o alcance e os impactos do trauma na vida psíquica como uma psicose passageira que leva à ruptura com a realidade ou à instalação de várias clivagens. Segundo Roussillon (1999), tanto a autoclivagem narcísica como a "clivagem do Eu" podem permitir conservar uma parte sã de si anestesiada sem se comunicar com a outra parte sofredora.

Alguns estudos recentes (Mazoyer et al., 2013; Mazoyer \& Martineau, 2011; Mazoyer \& Roques, 2014; Mazoyer \& Sanchez, 2015) tratam das repercussões psíquicas do abuso, tanto na infância como na adolescência, e apontam que esses traumatismos são revividos nas problemáticas de constituição da identidade, do édipo adolescente e na vida adulta. Nos adultos, esses autores discutem sobre as repercussões dos traumatismos sexuais incestuosos sobre a vivência da maternidade e da parentalidade. Janin (1996), por sua vez, entende as repercussões do abuso na vida adulta como uma segunda cena do traumatismo que produz um despedaçamento dos arranjos constituídos em torno de um segredo protetor do psiquismo, dificultando a simbolização dos fatos da violência sexual. Nesse sentido, consideramos que o impacto psíquico dos traumas sexuais intrafamiliares (como o incesto) na dinâmica afetiva de mulheres adultas, tem uma consequência no destino dos afetos, no funcionamento psíquico dessas mulheres e podem ser analisados por meio da avaliação com métodos projetivos em uma abordagem psicanalítica.

\section{METAPSICOLOGIA DO AFETO}

Para a psicanálise, o estado afetivo pode ser penoso ou agradável, se apresentar como uma descarga massiva, tonalidade geral (Laplanche \& Pontalis, 2004) ou, ainda, de acordo com Chabert (2010), como uma linguagem fisiológica. Ao retomar a obra freudiana, Roussillon (2005) retrata quatro formas de afeto, desde a mais corporal até a mais integrada psiquicamente: a sensação, a paixão (com o fracasso do afeto compartilhado), a emoção (com a participação do aspecto quantitativo) e o sentimento (a intensidade modulada no Eu). Green (1973) sintetiza a 
importância do afeto colocando-o no centro da regulação da vida psíquica. Esse breve panorama metapsicológico favorece a compreensão do afeto como sendo central na constituição subjetiva e na regulação psicossomática.

Ao iniciar um diálogo com as outras disciplinas, notadamente com os biólogos, Roussillon (2005) se interessa pela composição do afeto na sua relação aos primeiros objetos de investimento, particularmente nas clínicas das patologias narcísicas identitárias. Para o autor, a descarga psíquica do afeto apresenta duas facetas necessárias para o bom funcionamento do psiquismo: atividade de auto-observação (pelo afeto-sinal) e sensações de prazer-desprazer (aspecto quantitativo puro). As descargas somáticas e psíquicas podem ser dissociadas, ou pelo contrário, congruentes.

Como aponta Bion (1962), por exemplo, as sensações, as percepções e as experiências sentidas corporalmente devem ser transpostas em um plano psíquico. No entanto, o processo de representação depende das respostas dos primeiros objetos. A primeira representação do afeto, a passagem do afeto somático ao afeto-sinal, envolve, portanto, o reconhecimento pelo ambiente primário das experiências vivenciadas pelo bebê. Esse se vê nesses enfrentamentos refletidos pela mãe e passa pela experiência de diferenciação do seu estado interno. O objeto primário, pela sua empatia, dá sentido a esses enfrentamentos.

Se ligarmos o processo de representação à teoria freudiana da angústia (Freud, 1926/2016), a angústiatransbordamento, muito comum nas situações de abuso sexual, tem toda uma faceta passional. Para Roussillon (2005), o abuso sexual somente a posteriori se apresenta como uma experiência ameaçadora não recalcada e não transformada em sinal, consequentemente, a criança pode reagir instaurando um retraimento ou uma clivagem. A articulação dos trabalhos freudianos, notavelmente aqueles sobre a angústia e aqueles de Winnicott (1975) (sobre o espelho primário), permitem compreender o fracasso da construção do afeto como sinal de alarme e proteção contra os traumatismos do abuso sexual incestuoso.
O conceito psicanalítico de afeto permite averiguar a importância dos desafios intersubjetivos na constituição psíquica do sujeito. Essa constituição se organiza, claramente, a partir da experiência com o outro. $\mathrm{O}$ afeto emerge da ligação com os primeiros objetos e como esses últimos se ligam ao sujeito. Portanto, traumatismo e afeto se encontram em uma relação recíproca, o afeto pode ser protetor (dependendo se a sua função como um sinal de alarme foi constitutiva) ou falhar e ser desorganizador (reativando a passividade ou a angústia) (Green, 1999). O afeto específico do arrombamento traumático, no caso o terror, que pode ser vivido no abuso, instaura uma imagem traumática dentro do aparelho psíquico sem que ela possa se associar a outras representações e se constituir enquanto lembrança. Somente a posteriori do evento traumático a angústia pode dominar e se expressar por uma ansiedade de fundo, ou por formas agudas de ataques de pânico (Damiani \& Lebigot, 2011).

No caso da clínica do abuso sexual, o afeto se torna central tanto na perspectiva do abusador como da vítima. Estudos sobre os protagonistas de agressões sexuais e criminais (Chagnon, 2012; Ciavaldini, 2005) mostram que eles se encontram psiquicamente "clivados" da possibilidade de reconhecer e identificar os seus afetos e, por consequência, os afetos dos outros. Estudos sobre as vítimas mostram o impacto da violência e do traumatismo na psicodinâmica e no afeto desses sujeitos (Meyers, 1990; Lucchese et al., 2017; Jung, 2006), particularmente na vida afetiva e na autoestima. Entretanto, estudos mais específicos sobre a psicodinâmica dos afetos das vítimas que perderam uma parte da sua subjetividade no incesto são mais escassos, e com isso, importantes de serem realizados, principalmente em se tratando dos impactos do incesto na infância e adolescência na psicodinâmica do afeto na vida adulta. Nesse sentido, este estudo tem como objetivo analisar o destino e a dinâmica dos afetos de mulheres adultas que sofreram incesto durante a infância e adolescência.

\section{MÉTODO}

Trata-se de uma pesquisa descritiva-exploratória sobre os destinos dos afetos na dinâmica psíquica de mulheres que sofreram abuso sexual paterno na infância e adolescência. Para abarcar esse tema complexo, utilizou-se o estudo de casos múltiplos (Stake, 2011). De acordo com Verztman (2013, p. 71), "um estudo de caso [...] é uma forma de estudo que visa à descrição e a compreensão do singular" acreditando que este possa contribuir para a compreensão mais aprofundada de realidades subjetivas. A escolha de casos múltiplos, não visou à replicação, mas à possibilidade de criar linhas de divergência e convergência, sem a pretensão de avaliar a incidência dos fenômenos, mas sim entender o contexto no qual ele se produziu. Assim, segundo
Yin (2005), nosso estudo foi do tipo descritivo-exploratório visando responder como as participantes são impactados nos seus afetos pelos acontecimentos incestuosos. No contexto das pesquisas em saúde mental, no qual questões íntimas e delicadas são abordadas, as entrevistas e os procedimentos projetivos ganham destaque por criarem um campo promotor por meio do estabelecimento de uma relação transferencial (Turato, 2000).

\section{Participantes}

Essa pesquisa foi realizada com três mulheres francesas, na faixa etária de 30 a 40 anos de idade encontradas em 
centros de atendimento terapêutico dedicados às vítimas de abuso sexual na França. Essas mulheres sofreram abuso sexual por parte do pai durante a infância e adolescência e estão em atendimento clínico.

\section{Instrumentos}

Foram realizadas entrevistas clínicas e o método projetivo de Rorschach. Esse instrumento foi aplicado, codificado e analisado pela abordagem da Escola de Paris (Chabert, 1998; Rausch De Traubenberg, 1970), com enfoque psicanalítico.

O método de Rorschach evidencia os efeitos do traumatismo no corpo, de acordo com a perspectiva metapsicológica da ressonância afetiva ao Rorschach. Além disso, favorece uma identificação minuciosa das modalidades afetivas devido ao seu material específico (sensibilidade às pranchas coloridas e acromáticas e receptividade do sujeito ao ambiente). Pelas suas características perceptíveis (eixo vertical) e suas solicitações latentes, as pranchas do Rorschach ativam a interrelação entre percepção e projeção na articulação de experiências sensoriais e representacionais. A Tabela 1 apresenta as solicitações latentes das pranchas.

O Rorschach também pode ser qualificado como uma prova identitária, pois, ao testar os limites dentro-fora, permite avaliar a solidez dos processos de individuação. Segundo a Escola de Paris (Rausch De Traubenberg, 1970; Chabert, 1998) e, de forma mais geral, segundo uma perspectiva psicanalítica, o Rorschach é baseado no apelo ao corpo e aos afetos.

\section{Procedimentos}

\section{Aspectos Éticos}

Na França, para a realização de pesquisa clínica não é obrigatório a apresentação de projeto a um comitê de ética, como no Brasil. No entanto, todos os procedimentos éticos foram seguidos na realização dessa pesquisa. Houve consentimento livre explícito dessas mulheres para participação na pesquisa e todas estavam em acompanhamento terapêutico. Cada participante assinou um termo de consentimento no qual constava que se tratava de uma pesquisa com participação voluntária e na qual haveria a liberdade para recusar, retirar o consentimento ou interromper a participação a qualquer momento. Além disso, qualquer informação que pudesse revelar a identidade da participante e comprometer o anonimato foi devidamente retirada na descrição dos casos. Para esse efeito, nomes fictícios foram utilizados para identificar os casos clínicos.

Tabela 1

Solicitações latentes das pranchas do método de Rorschach

\begin{tabular}{|c|c|}
\hline Pranchas & Solicitações Latente \\
\hline I & $\begin{array}{l}\text { Prancha que evoca relações precoces. Primeiro contato com o teste, o que pode trazer à tona a experiência de entrar em } \\
\text { contato com um objeto desconhecido. }\end{array}$ \\
\hline II & $\begin{array}{l}\text { Prancha tricromática (preto, vermelho, branco), ela é construída em torno de configuração bilateral. Ela se associa à imagens } \\
\text { simbióticas fusionais e/ou destruidoras. Em outro registro, o sujeito é confrontado com a ameaça da castração ou de } \\
\text { destruição do corpo. }\end{array}$ \\
\hline III & $\begin{array}{l}\text { Solicita o processo de identificação sexual, do fato da bissexualidade manifesta dos personagens. No que diz respeito às } \\
\text { representações de relações, as evocações são menos brutais que com a prancha anterior. }\end{array}$ \\
\hline IV & $\begin{array}{l}\text { Solicita a posição do sujeito frente a imagens de potência fálica, podendo igualmente fazer retornar à imago materna. } \\
\text { Identificação da receptividade, passividade. }\end{array}$ \\
\hline $\mathrm{V}$ & $\begin{array}{l}\text { A prancha mais unitária do material: considerada como a da identidade e da representação de si. Aqui é possível perceber } \\
\text { identidades dissociadas. }\end{array}$ \\
\hline VI & $\begin{array}{l}\text { Prancha sexual caracterizada pela bissexualidade. Essa prancha permite que o sujeito faça a escolha identificatória abrindo } \\
\text { lugar para a bissexualidade psíquica. }\end{array}$ \\
\hline VII & $\begin{array}{l}\text { Essa prancha possui uma ressonância maternal. Ela permite ilustrar as diferentes modalidades das relações com a imagem } \\
\text { materna. }\end{array}$ \\
\hline VIII & As pranchas, pastéis, facilitam a regressão e o contato com o mundo externo. \\
\hline IX & $\begin{array}{l}\text { Essa prancha é a mais recusada. As cores e as formas se interpelam e o sujeito tem dificuldade de manter a firmeza dos seus } \\
\text { limites. Alguns se deixam levar pela regressão, outros não se sentem engolidos. }\end{array}$ \\
\hline$X$ & $\begin{array}{l}\text { A última prancha põe à prova a individuação e a separação. Quanto mais dificuldades de se separar do teste, mais respostas } \\
\text { terá nessa prancha. }\end{array}$ \\
\hline
\end{tabular}

Nota. Adaptado de Chabert (2003b). 


\section{Coleta de Dados}

Após uma primeira entrevista, na qual foram expostas as condições da pesquisa e os procedimentos éticos, o segundo encontro abarcou as suas histórias de vida e as repercussões das violências sexuais. No terceiro encontro, foi realizado uma avaliação psicológica com o Rorschach. No quarto encontro, um mês após a realização dos testes projetivos, foi proposta uma entrevista clínica devolutiva. Nessa entrevista, foram comunicados elementos da anamnese, aspectos do tratamento dos afetos encontrados nos protocolos projetivos e o sentimento contratransferencial que foi percebido durante esses encontros clínicos. Seguindo as recomendações de Green (1973), houve uma atenção especial, por parte das pesquisadoras, direcionada particularmente às palavras, às entonações da voz, aos silêncios e a todas as expressões emocionais.

\section{Análise dos Dados}

A fim de qualificar a análise da dinâmica dos afetos, utilizou-se a grade de análise do Rorschach proposta por Emmanuelli et al. (2005), apresentada na Tabela 2. Essa grade permite uma abordagem qualitativa de análise para as prancha do Rorschach, evidenciando as observações afetivas durante a aplicação (prazer, desagrado e angústia), a tonalidade dos afetos verbalizados, a dimensão econômica (da mínima à massiva), a ligação do afeto com a representação (tratamento do afeto) e as modalidades.

Tabela 2

Grade de análise dos afetos (A) no método de Rorschach

\begin{tabular}{lllllllllllllll}
\hline & I & II & III & IV & V & VI & VII & VIII & IX & X & Escolha \\
\hline & & & & & Tonalidade das marcas afetivas & & & &
\end{tabular}

Marcas de (A) de prazer

Marcas de (A) de desprazer

Marcas de (A) de angústia

Tonalidade dos afetos verbalizados

(A) indiferença

(A) positivo (prazer, alegria, felicidade amor)

(A) negativo (desprazer, tristeza, desamor, cólera, ciúmes, ódio)

(A) angústia

Dimensão econômica dos afetos
(A) mínima
(A) presente
(A) forte
(A) massiva

Modalidade de Expressão dos afetos

(A) expresso

(A) adiado

(A) abstrato

Verbalização de comportamento traduzindo o (A)

Modalidade de Tratamento dos afetos

Sem expressão de (A)

(A) sem ligação

Ligação A- Rppe

Ligação A- R não ppe

(A) sintônico

(A) inadequado

Defesas /Afetos

Denegação

Anulação

Intelectualização

Nota: Emmanuelli et al. (2005). 


\section{RESULTADOS}

Os estudos de casos serão apresentados considerando dados das entrevistas clínicas, aspectos da relação transferencial estabelecida com o clínico-aplicador e os resultados qualitativos da análise do Rorschach relativos ao destino dos afetos dessas mulheres com enfoque na grade de análise dos afetos proposta por Emmanuelli et al. (2005).

\section{Caso I: Claudine}

Claudine, 30 anos de idade, é divorciada e mãe de uma filha pequena. Ela apresenta comportamentos alimentares compulsivos que a permitem manter o seu equilíbrio, apaziguando as angústias. Essas compulsões alimentares também podem ser analisadas como uma forma de ataque ao próprio corpo, como se ela se sentisse culpada das agressões antigas vivenciadas, uma forma de masoquismo moral (Chabert, 2003a; Rosenberg, 1999).

Abusada sexualmente pelo pai, desde os quatro anos de idade até o fim da adolescência, ela somente relatou esses fatos após os 30 anos de idade, depois de repetidas violências no seu relacionamento conjugal. Isolada da família, ela rompeu totalmente as relações com o pai, mas continuou em contato com a mãe, mesmo que ela não reconhecesse a gravidade da violência sexual. Claudine ajuda vítimas de abuso, estimando não precisar de qualquer tipo de suporte terapêutico.

No Rorschach de Claudine os afetos são frequentemente expressos, exceto na prancha III (segunda prancha vermelha). Eles são retratados de forma impactante, principalmente quando sua tonalidade se revela negativa nas expressões: "terrível", "medo", "aterrorizante". No entanto, Claudine verbaliza comentários afetivos de prazer (pranchas V, VI, VII), de desagrado (pranchas II, VIII) e, até mesmo, de angústia (pranchas VII, IX, X). Os comentários nas últimas pranchas, no entanto, são dados fora das respostas do Rorschach e assumem uma forma de prova corporal bruta. Por exemplo, ela comenta na prancha VIII, "não me sinto à vontade", "uffffff...." (expressando desagrado).

As respostas ao Rorschach são acompanhadas de verbalizações de afetos majoritariamente negativos (pranchas I, II, V, VI, IX), melancólicos (Chabert, 2003a) e de angústia (pranchas I, III, IV, VII, X). Há uma nuance insuficiente de afetos positivos (pranchas IV, V, IX, X), denotando a presença de afetos melancólicos. Mesmo quando o afeto não é expresso diretamente, o corpo se torna o porta-voz com conteúdos mórbidos como as respostas "esmagado", "esfolado" que traduzem diretamente como o corpo é afetado (pranchas I, IV) e como a representação de si é desvalorizada.

Em relação ao tratamento dos afetos (Emmanuelli et al., 2005) no Rorschach de Claudine, ele nem sempre está ligado de maneira adequada com a representação pulsional.
Algumas vezes, o afeto comparece de forma sintônica na condição de que a representação de si seja idealizada, na forma de superlativos, majoritariamente manifestados de forma inadequada. Por exemplo, a risada acompanha respostas desvitalizadas ou anatômicas na prancha III. Ou ainda, o afeto é expresso direcionado, primeiramente, ao prazer e rapidamente muda para desprazer e angústia (pranchas I, IV, V, IX, X). Durante a produção das respostas no protocolo de Rorschach o afeto é sintônico com a representação, no inquérito ele se torna dissonante. Essa distorção repentina (particularmente nas pranchas V, VII, $\mathrm{IX}, \mathrm{X}$ ) reenvia à presença de mecanismos defensivos tais como a clivagem. Na prancha VII, onde o afeto se deforma, Claudine comenta: "é alegre, é estranho", ao mesmo tempo em que a percepção se degrada, ela diz em seguida: "eles quebraram o desenho em dois", testemunhando uma unidade perdida. A clivagem é repetida na prancha $\mathrm{X}$ com respostas antagônicas: "o bom" e "o obscuro". Os mecanismos de defesa são essencialmente a projeção (que participa da degradação dos traços perceptivos) e a clivagem.

Em síntese, no Rorschach de Claudine, o afeto pode ser expresso, mas ele está deformado tendo em vista a falta de continuidade e constância. Isso nos leva à seguinte questão: será que o incesto deformou o afeto e sua qualificação? $\mathrm{O}$ que fascina parece estar preenchido de inquietação, como ela demonstra diante do comentário na X: "É belo e inquietante como flores carnívoras".

\section{Caso 2: Doryne}

Doryne, atualmente com 40 anos de idade, mãe de três crianças (de três a 11 anos), é casada há quase 20 anos e vivenciou o incesto paterno dos oito aos 15 anos de idade. Doryne é realizada profissionalmente e sua relação conjugal é fortemente investida: ela diz inclusive "se segurar sempre em alguém".

Durante a gravidez do primeiro filho e após a morte do pai, ela é confrontada com o retorno parcial de uma cena traumática ligada às lembranças do incesto. Esses flashbacks são reativados durante a segunda gravidez (um segundo menino), quando ela informa à mãe sobre o abuso. Essa parece não se afetar, nem se surpreender muito e relata que a irmã de Doryne também vivenciou abuso paterno. Doryne desaba quando constata o déficit de proteção da mãe e a ausência de apoio atual. Esgotada pelos cuidados com essas duas crianças pequenas, transbordada por expectativas e necessidades, sem poder aliviar as suas angústias, acredita que está "enlouquecendo" e, ao participar dessa pesquisa, faz uma demanda de começar uma psicoterapia.

Antes de se recordar dessas lembranças do abuso paterno, que até então estavam mergulhadas no esquecimento, ela relata sempre ter se comportado como se fosse culpada, 
como se "houvesse [nela] algo de mal". O seu discurso, pontuado por numerosos silêncios entre os relatos, vem acompanhado de fortes emoções (choros) quando ela revisita essas lembranças. Nesses momentos é experimentado um vazio, uma forte opressão e sensações de vertigem. O traumatismo do abuso sexual se percebe nesses silêncios que mostram a resistência em se aproximar das cenas insustentáveis.

No Rorschach, ao contrário de Claudine, Doryne retém os seus afetos. Esses são, na maior parte, representações mórbidas com apelo ao corpo danificado e limites invadidos, por exemplo nas respostas: "buraco", "sangue", "cortada" e "desmembrado". Os questionamentos e outras solicitações de apoio ao clínico ao longo da aplicação do Rorschach traduzem uma demanda de reasseguramento. Se os afetos são pouco presentes, em contrapartida, o comportamento, notavelmente os numerosos risos, aparecem discordantes das respostas projetivas. As sensações são verbalizadas, mas salientam o registro da clivagem como, por exemplo, na prancha IV, ela diz: "ficamos no mórbido, é engraçado".

Os mecanismos defensivos são principalmente a racionalização e a compulsão à repetição. $O$ recurso à realidade está presente em todo o protocolo. Ao tentar apagar o lado inquietante das representações, como se elas não pudessem existir, ela diz na prancha VIII: "não é bem uma coluna vertebral, falta um pedaço de vértebra". No Rorschach de Doryne, a distorção do afeto é muito pontual e está em articulação com a clivagem, ela ocorre principalmente em relação às representações corporais alteradas, revelando os efeitos do incesto no corpo.

\section{Caso 3: Fanny}

Fanny tem quase 40 anos de idade, é órfã de mãe desde os oito anos, e de pai quando era jovem adulta. Ela banaliza esses acontecimentos que, à primeira vista, parecem traumáticos, e não toca mais no assunto durante os encontros. Sobre o abuso paterno ela fala que pouco tempo depois da morte da mãe, seu pai adotou com ela comportamentos sexualizados, sob o pretexto de despertar o seu corpo para a sensualidade. Ele fez isso, inicialmente, com o exercício da masturbação, logo depois, incentivou-a a ter relações sexuais com outros homens além dele.

No entanto, Fanny somente saiu do domicílio paterno no final da adolescência e nunca mais viu o pai vivo. Segundo Fanny, as práticas sexuais paternas foram legitimadas após a morte da sua mãe. No momento da pesquisa, Fanny já tinha uma filha quase adulta de um casamento que terminou em divórcio. Atualmente, ela busca encontros sexuais com homens que a repugnam e a maltratam sexualmente. Segundo seu relato, esses encontros não mobilizam afetos positivos, como se eles estivessem evacuados da cena psíquica.

Essa indiferença ao outro pode explicar a dificuldade vivenciada por Fanny de expressar os afetos de forma sintônica com a representação, ou até mesmo, com as sensações verbalizadas no Rorschach. Por exemplo, na prancha VI ela diz: "nunca é algo alegre, mas pelo menos ele não morreu esmagado", "mesmo se a cor é cinza". Há, todavia, algo de alegre, mas é como se o objeto primário não pudesse se ajustar à criança, nem reconhecer o efeito de suas ações e do mal-estar produzido. Na prancha VII, prancha materna, ela diz: "É até fofo", e na VIII ressalta: "Mesmo se é colorido, eu não acho que haja necessariamente muita alegria". Os mecanismos de defesa no seu protocolo de Rorschach são marcados por uma atmosfera inquietante, na forma de numerosos choques (ao preto, a cor e ao cinza), com uma sensibilidade acentuada ao preto, traduzindo o afeto melancólico (Chabert, 2003a). Os conteúdos são claramente disfóricos e a percepção (a qualidade dos traços mnêmicos) é alterada por eles. A intencionalidade das ações e dos comportamentos dos personagens percebidos ao longo do protocolo de Rorschach reforçam o mal-estar sentido, fortemente enfatizado pela reatividade sensorial e por cenas "estranhas", que testemunham sua dissociação. Por exemplo, na prancha I ela diz: "olhar para o próprio interesse"; na prancha II "parabenizar-se do mal que eles fizeram"; na prancha III "bater nos úteros dos outros". Os conteúdos mórbidos que comparecem no Rorschach indicam uma melancolização do afeto (Chabert, 2003a), a presença do narcisismo negativo (Green, 1973) e um envelope corporal danificado - como ilustrado na prancha IV "animal esmagado" e na prancha VI "tigre morto". Diante desses conteúdos mórbidos, os afetos que emergem são da indiferença e solidão. Ninguém pode cuidar da dor, nem se preocupar por esse animal que ela evoca, no qual Fanny parece projetar suas vivências infantis. Os mecanismos de defesa apresentados são do tipo projeção e dissociação, com numerosas perseverações no tema do nascimento, da procriação e das respostas desvitalizadas.

A distorção do afeto não pode ser necessariamente compreendida como uma atração/fascinação e repulsa pelo mesmo objeto como com Claudine. O protocolo de Fanny mostra um déficit na qualificação dos afetos pelo ambiente, como se a angústia não tivesse sido reconhecida nem nomeada.

\section{DISCUSSÃO}

A análise dos casos dessa pesquisa evidencia que as experiências traumáticas de abuso sexual realizados por figuras parentais na infância e adolescência produzem repercussões evidenciadas na vida adulta, tanto nos afetos e nos vínculos afetivos conjugais como também nas experiências com a maternidade. As repercussões desse tipo 
de traumatismo corroboram estudos realizados sobre o tema que consideram os impactos dessa violência no destino dos afetos e na auto-estima (Jung, 2006; Matias, 2006; Mazoyer et al., 2013; Mazoyer \& Martineau, 2011; Mazoyer \& Roques, 2014; Mazoyer \& Sanchez, 2015; Meyers, 1990).

Essa realidade é particularmente evidenciada pela história de Claudine, marcada pelo aprés-coup dos eventos incestuosos, mostrando um ciclo de repetições traumáticas dessa experiência afetiva nas suas relações conjugais. No seu caso, o abuso se constitui enquanto uma repetição buscada nas relações amorosas e o afeto, ainda que expresso no protocolo de Rorschach, se apresenta deformado. Doryne, por sua vez, reativa lembranças parciais das cenas incestuosas somente na gravidez. O traumatismo parece ter produzido uma espécie de branco psíquico das representações afetivas (Green, 1976). Somente na gravidez, com as modificações do corpo, dos seus limites e a reativação do tema da representação materna primária, elementos psíquicos do traumatismo (Belot \& Maidi, 2015) e da identidade feminina (Agostini, 2000) foram reavivados.

Ao contrário de Claudine, Doryne retém os afetos no Rorschach, geralmente com apelo ao corpo danificado e aos limites invadidos. O terceiro caso tem experiências de vida ainda mais agravantes. De fato, Fanny vivenciou, além dos abusos do pai e de outros homens, a morte da mãe, denotando a vulnerabilidade física e psíquica na infância e adolescência. Em sequência, na vida adulta, a busca por encontros afetivos se passa na forma da repetição de uma posição masoquista. No Rorschach de Fanny, os afetos não são expressos de forma sintônica com a representação, denotando a experiência da clivagem e da melancolização dos afetos com recurso à condutas masoquistas (Chabert, 2003a) e a presença do narcisismo negativo em um envelope corporal danificado (Green, 1973).

Com isso, os protocolos de Rorschach mostram que, para além da presença do afeto melancólico (Chabert, 2003a), comparece a distorção do afeto e a perda da sua qualidade psíquica. $\mathrm{O}$ termo distorção faz referência à deformação e ao movimento de descontinuidade na qualificação do afeto. Tal distorção pode ser compreendida por uma vivência emocional desqualificada pelo ambiente que falhou em poder significar as mensagens recebidas, como no caso de Fanny. Ou, até mesmo, pela própria vivência afetiva excluída, tanto pela submissão ao desejo do outro parental como pela identificação com o agressor. De todo modo, nota-se que a presença maciça da identificação projetiva e da clivagem levam o afeto, muitas vezes, a não ser apresentado de forma sintônica com a representação, como nesses exemplos de respostas: "nunca é algo alegre mas pelo menos ele não morreu esmagado"; "Mesmo se é colorido, eu não acho que haja necessariamente muita alegria". Nesse sentido, retomamos Ferenczi (1933/2004) que ressalta o alcance e os impactos do trauma na vida psíquica com a instalação de várias clivagens, inclusive dos afetos. Esse autor, ao discutir o impacto do traumatismo decorrente da confusão de línguas entre a vítima e o agressor, mostra o quanto a mulher abusada sexualmente é invadida psiquicamente pelo abusador, aumentando o risco de ausência de diferenciação, tendo em vista a confusão incestuosa com o corpo da mãe.

Ao se considerar a regressão e os significados latentes das pranchas maternas do Rorschach (prancha VII, "é até fofo"Fanny; "é alegre, é estranho" - Claudine) é possível notar nas respostas uma ansiedade de contato, um estranhamento em relação ao objeto maternal e também ao destino do feminino (Mazoyer \& Martineau, 2011). Para Roussillon (2015), a sexualidade infantil não pode ser discutida sem sua ancoragem corporal e sem considerar o papel do objeto em sua constituição. A esse propósito, Roussillon (2009) reafirma que o objeto deve permitir que essa experiência ruim, a ser evacuada, possa se tornar uma experiência a ser simbolizada. O início da simbolização está, portanto, na intersubjetividade. Sendo assim, quando essas mulheres são violadas e o ambiente responde de forma inadequada ou até mesmo silenciosamente, a violação do afeto e do pensamento é reforçada. O sexual infantil fracassa em exercer a função de atribuir sentido, o que provoca o efeito catastrófico do incesto. Por consequência, é como se o Eu não fosse capaz de lidar com afetos ligados à experiência sexual ou extremamente violenta.

Ao solicitar a projeção, o Rorschach fornece protocolos que são vividos e lidos como pesadelos acordados, com conteúdos mórbidos ("tigre morto e "animal esmagado") e corpos molestados e atingidos ("não é bem uma coluna vertebral, falta um pedaço de vértebra"). Segundo Calamote (2016), nos sujeitos que atravessaram experiências traumáticas a questão não é tanto o conteúdo, mas sim o tema do corpo fragmentado, evidenciado no Rorschach pelas representações corporais danificadas com limites invadidos, como nas respostas: "buraco", "sangue", "cortada", "desmembrado" ou respostas bizarras como "bater no útero dos outros". Parat (2011) insiste em falar sobre uma privação de simbolização do afeto devido a incapacidade de distinção entre o sonho e a realidade.

Em suma, essas mulheres compartilham experiências traumáticas e precoces da sexualidade com consequências claras no destino dos seus afetos na vida adulta. Conforme aponta Roussillon (2005), uma experiência ameaçadora, não recalcada, que não se transforma em sinal de alarme e proteção contra as invasões no psiquismo pode instaurar retraimentos ou clivagens. De maneira geral, a análise das entrevistas e dos destinos dos afetos no Rorschach, por meio da grade proposta por Emmanuelli et. al (2005), nas mulheres vítimas de incesto, pode potencializar novas investigações na prática clínica além de trazer contribuições para o desenvolvimento de pesquisas sobre as psicoterapias nesse contexto.

Esse modelo de pesquisa descritiva-exploratória, com investigação qualitativa de casos, traz contribuições para o trabalho clínico terapêutico com mulheres marcadas por situações de incesto e evidenciam a importância do 
trabalho sobre a identificação, reconhecimento e manejo dos afetos nos encontros terapêuticos. Como coloca Parat (2004, 2011), a clínica do incesto nos convida a refletir sobre as modalidades de trabalho terapêutico possíveis com as mulheres que foram vítimas de abuso sexual na infância e adolescência. Um dos eixos de aproximação dessa clínica refere-se à abordagem do estado afetivo (Parat, 2004, 2011), inclusive com suas repetições na transferência na psicoterapia.

Com isso, entende-se o valor dos estudos com métodos projetivos nessa área, já que apelam às pulsões, ativam a regressão e colocam o sujeito em face ao perigo das catástrofes de simbolização do afeto (Roman, 2018), reavivando o modelo do trauma. Diante disso, o sujeito pode recorrer à clivagem, ao isolamento e cortar todo o investimento afetivo pelo medo de ser submerso e sobrecarregado. Sendo assim, os protocolos dessa pesquisa com análise qualitativa do Rorschach demonstram a deformação e distorção dos afetos e permitem sublinhar o perigo de um encontro psicoterapêutico baseado somente na livre associação e na representação, ou seja, no consequente relaxamento do controle de pensamentos e afetos. Com isso, recomendamos como proposição de pesquisa para a prática clínica, ajustes na estrutura terapêutica para evitar que o sujeito fique sozinho em face à reativação de experiências traumáticas e angustiantes (Winnicott, 1965/1994).

Na clínica do traumatismo precoce é essencial que o psicólogo, primeiramente, antes mesmo de trabalhar nas representações, se apoie no seu corpo, experiências, sentimentos, ressonâncias afetivas e sensoriais como ponto de referência para o manejo clínico (Estellon \& Marty, 2012; Pommier, 2008). A afetividade, segundo Parat (2013), é tanto um instrumento do conhecimento como também terapêutico. Ela provoca movimentação na cadeia associativa e promove a passagem de um fato traumático expresso na forma de reavivamento corporal - constantemente atualizado pelo sensorial - para a constituição como memória, na forma de reminiscência psíquica. No encontro terapêutico, é pela transferência com o clínico que essas mulheres podem vivenciar a experiência de compartilhar com o outro, não sem projetar, através da identificação projetiva, a angústia e o horror do vivido. A transferência é o motor da repetição dos afetos, serve de ancoragem para a recordação e, mais tarde, para a perlaboração (Chabert, 2010). A percepção do terapeuta torna-se, sem dúvida, essencial para desdobrar as marcas e cicatrizes afetivas. Esse primeiro momento permite desenhar progressivamente uma forma de experiência traumática e desconstruir várias camadas psíquicas (Mazoyer \& Roques, 2014).

De fato, nessas mulheres, a dificuldade ou incapacidade de falar algo de sua experiência afetiva pode ser um dos efeitos do trauma que comparece destruindo a temporalidade e condensando vários eventos. Além disso, as experiências de excitação sexual, por trás do aspecto barulhento do incesto, podem desviar o clínico da angústia e impotência sentida com brutalidade na contratransferência, tendo em vista a maciça mobilização da identificação projetiva (Mazoyer \& Roques, 2014). Consequentemente, o único indicador nessa clínica dos extremos (Estellon \& Marty, 2012) está nas sensações corporais ainda vivas e que podem ser reativadas e investigadas nos comportamentos compulsivos e excessivos bem como na transferencia com o terapeuta na psicoterapia. Dessa forma, torna-se possível qualificá-los e, principalmente, transformá-los.

Para finalizar, podemos considerar que esse estudo potencializa a realização de novas pesquisas com entrevistas e métodos projetivos. Além disso, investigações futuras com desenhos de pesquisa longitudinais, multimetodológicas e com casos clínicos acompanhados em psicoterapia podem aprofundar a discussão sobre a eficácia de processos terapêuticos no manejo da dinâmica afetiva de pacientes que sofreram traumatismos precoces.

\section{REFERÊNCIAS}

Agostini, D. (2000). Du délit d'initié à l'internalisation de la contrainte par corps: l'inceste. In D. Agostini (Ed.), Après Mélanie Klein: Monographie de la revue Adolescence (pp. 23-31). GREUPP. https://www.cairn.info/apres-melanie-klein-2825706604-page-23.htm

Balier, C. (1994). L'inceste: Un meurtre d'identité. La Psychiatrie de l'Enfant, 37(2), 333-351. https://www.ascodocpsy.org/ santepsy/index.php?lvl=notice_display\&id $=111274$

Belot, R. \& Maïdi, H. (2015). Deuil traumatique de la mère et expression somatique du bébé. La Psychiatrie de L'enfant, 58(2), 407-436. https://doi.org/10.3917/psye.582.0407

Bion, W. R. (1962). Une théorie de l'activité de pensée. In J.Y. Chagnon (Ed), Réflexion faite (pp. 125-135). Presses Universitaire de France.

Bollas, C. (1996). Les Forces de la destinée: La psychanalyse de l'idiome humain. Calmann-Lévy. https://doi.org/10.3917/ rfp.653.0925

Calamote, É. (2016). Peut-on se souvenir et parler d'une expérience traumatique: Les risques de l'investigation. Cahiers de
Psychologie Clinique, 47(2), 225-242. https://doi.org/10.3917/ cpc.047.0225

Chabert, C. (1998). Psychanalyse et méthodes projectives. Dunod coll Topos.

Chabert, C. (2003a). Féminin mélancolique. Presses Universitaires de France.

Chabert, C. (2003b). O Rorschach na clínica do adulto: Interpretação psicanalítica (J. P. da Silva \& L. A. Cunha, Trad.). Climepsi.

Chabert, C. (2010). L'affect dans 1'âme. Revue Française de Psychanalyse, 5(74), 1423-1431. https://doi.org/10.3917/ rfp.745.1423

Chagnon, J. (2012). Psychopathologie des auteurs d'agressions sexuelles. In V. Estellon \& F. Marty (Eds), Cliniques de l'extrême (pp. 131-150), Armand Colin.

Ciavaldini, A. (2005). L'agir: Un affect inachevé. In J. Bouhsira (Ed), L'affect (pp. 137-162). Presses Universitaires de France.

Damiani, C., \& Lebigot, F. (2011). Les mots du trauma: Vocabulaire de psychotraumatologie. P. Duval. 
Emmanuelli, M., Pheulpin, M. C., \& Bruguière, P. (2005). Un destin des affects dans la dépression: L'émoussement affectif. Élaboration d'une méthodologie de recherche a partir des épreuves projectives. Bulletin de Psychologie, 476(2), 195-205. https://doi.org/10.3917/bupsy.476.0195

Estellon, V., \& Marty, F. (2012). Cliniques de l'extrême. Armand Colin.

Ferenczi, S. (2004). Confusão de língua entre os adultos e a criança. In Obras completas, 4 (pp. 97-106). (Obra original publicada em 1933)

Freud, S. (2016). Inhibition, symptôme et angoisse (8a ed.). Presses Universitaires de France. (Obra original publicada em 1926)

Green, A. (1973). Le discours vivant. Presses Universitaires de France.

Green, A. (1976). Le concept de limite. In La folie privée (pp. 103-140). Gallimard.

Green, A. (1999). Passivité-passivation: Jouissance et détresse. Revue Française de Psychanalyse, 63(3), 1587-1600. https:// www.cairn.info/revue-francaise-de-psychanalyse-1999-3page-1587.htm

Janin, C. (1985). La réalité et son objet: propositions théoriques. Revue Française de Psychanalyse, 49(2), 667-677. http:// mapageweb.umontreal.ca/scarfond/T6/6-Janin.pdf

Janin, C. (1996). Figures et destins du traumatisme. Presses Universitaires de France.

Jung, F. (2006). Abuso sexual na infância: Uma leitura fenomenológica-existencial através do Psicodiagnóstico Rorschach [Dissertação de mestrado]. Repositório da Universidade Católica de Goiás. http://tede2.pucgoias.edu. br:8080/bitstream/tede/1847/1/Flavia\%20Hermann\%20Jung. pdf

Laplanche, J., \& Pontalis, J. B. (2004). Vocabulaire de la psychanalyse (4a ed.). Presses Universitaires de France.

Lucchese, G. S, Avoglia, H. R. C., \& Silva, P. O. (2017). A dinâmica psíquica e as estruturas defensivas da mulher vítima de violência doméstica. Boletim da Academia Paulista de Psicologia, 37(92), 24-39. http://pepsic.bvsalud.org/scielo. php?script=sci_arttext\&pid=S1415-711X2017000100004\&1 ng $=$ pt\&nrm $=$ iso

Matias, D. P. (2006). Abuso sexual e sociometria: Um estudo dos vínculos afetivos em famílias incestuosas. Psicologia em Estudo, 11(2), 295-303. https://doi.org/10.1590/S141373722006000200008

Mazoyer, A. V., Lebrun-Devemy, A. \& Roques, M. (2013). L'ombre de l'inceste paternel ancien sur la maternité: Désorganisation et réorganisation psychique. Psychothérapies, 33(3), 149-156. https://doi.org/10.3917/psys.133.0149

Mazoyer, A. V., \& Martineau, J.-P. (2011). Traumatisme de l'inceste et destin du féminin. Annales Médico-Psychologiques, 169(6), 383-386. https://doi.org/10.1016/j.amp.2011.05.004

Mazoyer, A. V., \& Roques, M. (2014). Mobilisation des processus psychiques chez des enfants victimes d'agression sexuelle. Bulletin de Psychologie, 532(4), 331-348. https://doi. org/10.3917/bupsy.532.0331

Mazoyer, A., \& Sanchez, C. (2015). Lecture clinique et projective du refus d'engagement dans la thérapie chez une femme victime d'inceste. Psychothérapies, 3(35), 185-193. https:// doi.org/10.3917/psys. 153.0185

Meyers, J. (1990). The Rorschach as a tool in understanding the dynamics of women with histories of incest. In H. D. Lerner \&
P. M. Lerner (Eds.), Primitive mental states and the Rorschach (pp. 203-228). International Universities Press.

Parat, H. (2004). Psychanalyse des agirs incestueux. In H. Parat (Ed.), L'inceste (pp. 80-107). Presses Universitaires de Paris. https://www.cairn.info/l-inceste--9782130541073-page-80. htm

Parat, H. (2011). Les destins de l'inceste. L'Évolution Psychiatrique, 76(2), 245-261. https://doi.org/10.1016/j.evopsy.2011.03.016

Parat, C. (2013). L'affect partagé. Revue Française de Psychosomatique, 44(2), 167-182. https://www.cairn.info/ revue-francaise-de-psychosomatique-2013-2-page-167.htm

Pommier F. (2008). L'extrême en psychanalyse. Campagne Première.

Rausch de Traubenberg, N. (1970). La pratique du Rorschach. Presses Universitaires de France.

Rosenberg B. (1999). Masochisme mortifère et masochisme gardien de la vie. Presses Universitaires de France. https:// doi.org/10.3917/puf.rosen.1999.01

Roussillon, R. (1999). Agonie, clivage et symbolisation. Presses Universitaires de Paris.

Roussillon, R. (2002). Jalons et repères de la théorie psychanalytique du traumatisme psychique. Revue Belge de Psychanalyse, 40, 25-42. https://www.psychanalyse.be/article/jalons-et-reperesde-la-theorie-psychanalytique-du-traumatisme-psychique/

Roussillon, R. (2005). Affect inconscient, affect-passion et affectsignal. In J. Bouhsira (Ed.). L'affect, Monographies de Psychanalyse (pp. 117-135). Presses Universitaires de France. https://doi.org/10.3917/puf.parat.2005.01.0117

Roussillon, R. (2009). La destructivité et les formes complexes de la « survivance » de l'objet. Revue Française de Psychanalyse, 73(4), 1005-1022. https://doi.org/10.3917/rfp.734.1005

Roussillon, R. (2015). Le sexuel infantile entre corps et objet-autresujet. Revue Française de Psychanalyse, 79(5), 1642-1648. https://doi.org/10.3917/rfp.795.1642

Roman, P., \& Baron, H. (2004). Le silence et la révélation: Violence sexuelle et souffrance du dire, au risque du clivage. Cahiers de Psychologie Clinique, 23(2), 59-79. https://www.cairn.info/ revue-cahiers-de-psychologie-clinique-2004-2-page-59.htm

Roman, P. (2018). L'inadvenu de l'affect et la trace du traumatique dans les violences sexuelles. Adolescence, 36(1), 109-120. https://doi.org/10.3917/ado.101.0109

Stake, R. E. (2011). Pesquisa qualitativa: Como as coisas funcionam (K. Reis, Trad.). Penso.

Turato, E. (2000). Introdução à metodologia da pesquisa clínicoqualitativa: Definição e principais características. Revista Portuguesa de Psicossomática, 2(1), 93-108. https://www. redalyc.org/pdf/287/28720111.pdf

Verztman, J. S. (2013). Estudo psicanalítico de casos clínicos múltiplos. In A. M. Nicolaci-da-Costa \& D. R. Romão-Dias (Eds), Qualidade faz diferença: Métodos qualitativos para a pesquisa em psicologia e áreas afins (pp. 67-92). Loyola.

Winnicott, D. W. (1975). Jeu et Réalité: L'espace potentiel. Gallimard.

Winnicott, D. W. (1994). O conceito de trauma em relação ao desenvolvimento do indivíduo dentro da família. In D. Winnicott, Explorações psicanalíticas (pp. 102-115). Artmed. (Trabalho original publicado em 1965)

Yin, R. K. (2005). Estudo de caso: Planejamento e métodos. Bookman. 